Focused Review

\title{
Drug-Related Side Effects of Long-term Intrathecal Morphine Therapy
}

From: Physicians' Pain Specialists of Alabama, Mobile, AL. Dr. Ruan is Associate Medical Director, Physicians' Pain Specialists of Alabma, and Director, Clinical Research \& Electrodiagnostic Testing Physicians' Pain Specialists of Alabama, Mobile, AL Address Correspondence: Xiulu Ruan, MD, 2001 Springhill Ave. Mobile, AL 36607 Email: xiuluruan@yahoo.com Disclaimer: There was no external funding in preparation of this manuscript.

Conflict of interest: None Manuscript received:12/05/2006 Revisions accepted: 2/13/2007

Accepted for Publication: $2 / 16 / 2007$

Free Full manuscript: www.painphysicianjournal.com
Background: The introduction of intrathecal opioid administration for intractable chronic non-malignant pain and cancer pain is considered as one of the most important breakthroughs in pain management. Morphine, the only opioid approved by FDA for intrathecal administration, has been increasingly utilized for this purpose. For over 3 decades, there have been numerous reports on the non-nociceptive side effects associated with ever increasing long-term intrathecal morphine usage.

Objectives: To review the literature on side effects due to long-term intrathecal morphine therapy with discussions of alternate treatment options.

Design: English-language publications were identified through MEDLINE search and the bibliographies of identified articles were reviewed.

Results: Most side effects of intrathecal morphine therapy are dose dependent and mediated by opioid receptors. Common ones include nausea, vomiting, pruritus, urinary retention, constipation, sexual dysfunction, and edema. Less common ones include respiratory depression, and hyperalgesia. Catheter tip inflammatory mass formation is a less common complication that may not be mediated by opioid receptors.

Conclusion: The utilization of intrathecal morphine administration for cancer and intractable non-malignant chronic pain represents an important leap forward in pain management. Yet, a wide variety of non-nociceptive side effects may also occur in susceptible patients. The side effects due to intrathecal morphine administration are mostly mediated by opioid receptors. Treatment usually involves the utilization of opioid receptor antagonist, such as naloxone. Patients considering intrathecal opioid pump therapy should be informed and advised about the possible side effects associated with longterm intrathecal morphine administration prior to placement of a permanent morphine infusion pump.

Key words: side effects, intrathecal morphine, opioid receptors

Pain Physician 2007; 10:357-365 
T he discovery of specific opioid receptors in the central nervous system in the 1970s marked a milestone for spinally mediated analgesia (14). In 1976, Yaksh and Rudy demonstrated the efficacy of intrathecal opioids in abolishing pain in animal models (4), and in 1979, Wang et al reported the first case of intrathecal administration of morphine used effectively for pain relief in humans (5). Since the 1980s, intraspinal drug delivery therapy has been increasingly utilized, first in cancer patients, later on in patients with non-malignant intractable pain who failed to respond to conventional treatment or could not tolerate systemic opioid therapy due to side effects. By infusing a small amount of analgesic directly into the cerebrospinal fluid in close proximity to the receptor sites in the spinal cord, one is able to achieve profound anti-nociception by the spinally mediated analgesia, sparing some of the side effects caused by systemic opioids (6-10). There are at least 3 distinct types of opioid receptors: mu, kappa, and delta. These are widely distributed in the brain, spinal cord, and around peripheral nociceptors (11). $\mathrm{Mu}$ receptors modulate responses to mechanical, chemical and thermal nociception at the supraspinal level. Kappa receptors appear to modulate spinally mediated thermal nociception and chemical visceral nociception. Delta receptors may modulate mechanical and inflammatory nociception (11).

Morphine, the only FDA approved opioid for intrathecal administration, is effective, inexpensive, and well tolerated by majority of patients (12). However, with the ever-increasing application of intrathecal morphine for intractable painful conditions, more and more clinically relevant side effects become evident.

\section{Pharmacokinetics of Intrathecal Morphine}

The side effects of intrathecal opioids are caused by the presence of an opioids either in the cerebral spinal fluid (CSF) or in the blood (13). Vascular uptake of opioids following intrathecal administration does occur to some degree, but it is clinically insignificant (1416). Almost all intrathecal opioid-related side effects are mediated by opioid receptors (13). However, the pharmacokinetics of intrathecally administered opioids varies significantly depending on its lipophilicity. Fentanyl, e.g., with high lipophilicity, penetrates the spinal cord rapidly, leaving little to ascend cephalic in the cerebral spinal fluid (CSF). In contrast, morphine, with high hydrophilicity, penetrates the spinal cord slowly, allowing a considerable amount of the drug to ascend cephalad in the CSF (13). The mechanism of cephalad migration of morphine is thought to be due to bulk flow of CSF (17), which ascends from the lumbar region, reaching the cisterna magna by $1-2$ hours and the fourth and lateral ventricles by 3-6 hours (17). Intrathecally administered morphine produces slower onset and longer duration of anti-nociception, but a higher incidence of certain side effects (13). The majority of the commonly seen pharmacological side effects while receiving intrathecal morphine therapy, such as pruritus, nausea/vomiting, urinary retention, constipation, mental status change, and respiratory depression, can be easily antagonized by the mu antagonist, naloxone (13). However, the analgesic effect may (18) or may not (19) be maintained. Side effects of intrathecal morphine therapy are usually common at the initiation phase of the treatment and generally resolve with standard medical management during the first 3 months (10). The incidence of drug-related side effects with long-term intrathecal morphine therapy decreases with medical management and dose reduction as therapy continues (10).

\section{Side Effects of Intrathecal Morphine}

\section{Pruritus}

Pruritus is one of the most common side effects associated with intrathecal morphine administration. Its incidence varies from 0 to $100 \%$ (13). It is mostly localized in the face, neck or upper thorax although it may also be generalized $(20,21)$. It is usually mild; severe pruritus only occurs in $1 \%$ of patients. It usually occurs within a few hours of drug administration and may even precede the onset of analgesia (22). The incidence of pruritus due to long-term intrathecal morphine administration is about $14 \%$ (10). Pruritus, induced by intrathecal morphine administration, is thought to be caused by cephalad migration of the drug in the CSF to interact with the trigeminal nucleus located in the superficial medulla (23). The trigeminal nucleus descends into the cervical spinal cord and connects with the substantia gelatinosa of the dorsal horn. The interaction of opioids in the substantia gelatinosa may initiate the "itch reflex" $(24,25)$. Altered CNS pain perception may also play a part in pruritus induced by intrathecal morphine (25). Rapid development of tolerance to itching usually occurs in 1-2 weeks after initiation of intrathecal morphine therapy (26). Pruritus can be readily treated with the mu antagonist, nal- 
oxone, IV drip at $5 \mathrm{mcg} / \mathrm{kg} / \mathrm{hour}$ without losing analgesia (26). Although opioids may enhance the release of histamine from mast cell by activating $\mathrm{H} 1$ receptor on itch-specific C fibers (11), it is unlikely for this to be the mechanism that causes pruritus in patients on intrathecal morphine therapy (13). Interestingly, antihistamines can be useful in treating pruritus caused by intrathecal morphine, likely due to its sedative effects (13). The proposed mechanism of opioid induced itching includes involvement of serotonergic receptors and/or mu and kappa receptors (11). The 5HT3-receptor antagonist, ondansetron (4-8mg PO Q8H prn), was found to decrease itching caused by intrathecal morphine $(27,28)$. Nalbuphine $(10 \mathrm{mg}$ IV/IM/SC Q3-6H prn), a mu antagonist and kappa agonist, was found to lessen itching in patients on intrathecal morphine without causing reversal of analgesia $(29,30)$.

\section{Nausea and Vomiting}

Nausea and vomiting are commonly seen with intrathecal morphine administration. Chaney noted the incidence of nausea and vomiting following acute intrathecal opioid administration to be $30 \%$ (13), although the incidence following long-term intrathecal morphine delivery is unknown. This incidence was found to be related to the intrathecal morphine dosage by Bailey et al (22), while Raffaeli et al found no clear correlation between the dose and the incidence of nausea and vomiting in opioid-naïve patients following intrathecal opioid administration (31). However, both of the above studies were done in patients following acute intrathecal morphine administration. Anderson et al reported the incidence of nausea as $21 \%$ in patients on long-term intrathecal morphine therapy, but was improved by dose reduction (10). Nausea and vomiting induced by intrathecal morphine are likely the result of cephalad migration of drug in the CSF and subsequent interaction with opioid receptors located in the chemoreceptor trigger zone (area postrema) (32-34). Sensitization of the vestibular system (35) and decreased gastric emptying (36) by opioids may also contribute to the development of nausea and vomiting. Positional changes may exacerbate these symptoms (31). Based on etiologies, different pharmacological regimens can be used to treat them, e.g., those secondary to vestibular stimulation (worsened by movement, position change) respond to meclizine $(25 \mathrm{mg}$ PO Q6H prn), promethazine $(25 \mathrm{mg}$ PO Q6H prn) and scopolamine (0.1 mg Patch Q $72 \mathrm{H})$; those secondary to constipation respond to metoclo- pramide (10mg PO Q6H prn), stool softners/or bowel stimulants; those secondary to chemoreceptor trigger zone stimulation respond to droperidol $(0.625-2.5 \mathrm{mg}$ IV/IM), hydroxizine (25mg PO Q6H prn), and prochlorperazine $(10 \mathrm{mg}$ PO Q6H prn) $(11,26)$. Some patients may require more than 2 different types of antiemetics simultaneously to achieve efficacy (37).

\section{Urinary Retention}

Urinary retention following intrathecal morphine administration has an estimated incidence between $42 \%$ and $80 \%(12,22)$ and is more common in elderly men with enlarged prostates $(12,22)$. It is much more common than following the administration of equivalent doses of morphine given intramuscularly or intravenously (38). The incidence of urinary retention with long-term intrathecal morphine therapy is only at $3 \%$ (10). It is believed to be dose independent (39). The interaction with opioid receptors in the sacral cord, resulting in the inhibition of sacral parasympathetic outflow and subsequent detrusor relaxation, is felt to be responsible for inducing urinary retention (40). This effect appears to be mediated by mu and delta, but not kappa receptors (41). Urinary retention has never been reported following intraventricular morphine administration, suggesting a spinally mediated mechanism (42). Endogenous opioids are suspected to play a role in bladder function control through modulation of parasympathetic outflow at the sacral cord level (43). The detrusor relaxation caused by epidural morphine in humans is readily reversed with naloxone (0.1-0.2mg Q $3 \mathrm{~min}$ prn IV/IM/SC) (40), although reversal of analgesia is also likely (44). Cholinomimetic agents such as bethanecol (10-30mg PO TID) may be helpful to treat urinary retention induced by opioids (45).

\section{Constipation}

Anderson et al found that $30 \%$ of the patients in their study experienced sconstipation at least once over a 2-year follow-up period (10). Intrathecal morphine may prolong the intestinal transit time $(46,47)$. The decreased gastrointestinal motility caused by intrathecal morphine is due to the interaction with opioid receptors in the spinal cord, rather than from systemic absorption $(47,48)$, even though systemic opioid is well known to cause constipation by a direct action on opioid receptors present in the gastrointestinal smooth muscle (49). Patients on intrathecal morphine therapy may present with signs and symp- 
toms of ileus, which, in turn, may cause nausea and vomiting (46-48). Some authors have recommended a prophylactic approach with cathartics $(42,49,50)$. The recommended guidelines include starting with a stool softner (e.g. docusate, $100 \mathrm{mg}$ PO bid) and a bowel stimulant (e.g. senna, 2 Tabs PO BID, bisacodyl, $10 \mathrm{mg}$ PO/PR prn), increasing dosages as needed before adding laxatives (e.g. mineral oil, glycerine suppositories) (49). Prokinetic agents such as metoclopramide $(10 \mathrm{mg}$ PO TID) or domperidone (10-20mg PO TID) can be added if the constipation has not responded to the above conventional treatments (49). Naloxone can readily reverse opioid-induced constipation, either induced centrally or peripherally, even though only $2 \%$ of the orally administered naloxone will reach the CNS due to extensive first-pass metabolism (51). Because of the very narrow therapeutic window of naloxone, which is prone to precipitating analgesic withdrawal, it is reasonable to start low (0.6-1 mg PO TID), titrate up as needed to $5 \mathrm{mg}$ PO TID (49).

\section{Fluid Retention}

Water retention and peripheral edema caused by intrathecal opioids can be quite problematic (52). Although the incidence of long-term intrathecal opioid induced edema ranges from $6.1 \%(12)$ to $21.7 \%(53)$, edema due to intrathecal morphine occurred in only $3 \%$ (10), $11.7 \%(54)$, and $16 \%$ (52), respectively in 3 different studies. Pharmacokinetic studies suggest the cephalad migration of morphine in the CSF, and subsequent interaction with opioid receptors in the posterior pituitary gland, stimulates vasopressin release by the posterior pituitary (13). Anderson et al noted only transient improvement of edema after changing intrathecal morphine to hydromorphone and recurrent edema following prolonged exposure to intrathecal hydromorphone (52). Aldrete et al observed leg/foot edema in $5 / 23$ patients on intrathecal opioids $(21.7 \%)$, compared to 2 of 5 on morphine; and 3 of 5 on oxymorphone (53). They also noted cases with severe pedal edema, seeping lesions that minimally responded to treatment with diuretics, compression stocking and pumps, only to lessen with opioid dose reduction, and in 2 severe cases, almost complete resolution of edema after infusion cessation. Treatment of intrathecal opioid-induced edema starts with simple measures such leg raising, elastic stockings, compressive air pumps, and salt and fluid restriction (49). Diuretics may also be used with benefit (49). Aldrete et al recommended that pre-existing leg venous insufficiency and edema be considered relative contraindication for intrathecal opioid therapy (53).

\section{Mental Status Change}

Mental status change, presented as sedation and lethargy, occurred in $10-14 \%$ of patients receiving long-term intrathecal morphine infusion therapy (10). The degree of sedation appears to be dose related (22). Profound CNS depression, i.e., coma, has been reported (55). Respiratory depression must be suspected whenever sedation occurs following intrathecal opioid administration (56). Mental status changes, apart from sedation, may also present as paranoid psychosis, catatonia, euphoria, anxiety, delirium and hallucination $(57,58)$. Cephalad drug migration in the CSF and subsequent interactions with opioid receptors in the brain such as the thalamus, limbic system and cerebral cortex is suggested (13). When these side effects are evident, opioid dose reduction should be tried first. Sedation can be treated with "traditional" psychostimulants such as methylphenidate (5-10mg PO QDBID prn) (59) or the "new" psychostimulatants such as modafinil (200-400mg PO QD prn) (60). Delirium and hallucination are treated with neuroleptics such as haloperidol (1-5mg PO BID prn) or benzodiazepines such as lorazepam (0.5-1 mg TID PO prn) (49).

\section{Sexual Dysfunction}

Impotency or decreased libido may occur more frequently than previously recognized by physicians (54). Abs et al studied 73 patients ( 29 male and 44 female) on intrathecal opioid therapy (68 with morphine; 5 with hydromorphone) for non-malignant pain. They noted decreased libido or impotency in 23 of 24 men receiving long-term intrathecal opioids (61). The serum testosterone levels in 23 males in the treatment group were significantly lower than the control group; decreased libido was reported in 22 of 32 women on intrathecal opioid therapy. Significantly lowered serum LH, FSH were found in all 18 postmenopausal females. All 21 premenopausal females developed either amenorrhea or irregular menstrual cycles with lowered serum LH, estradiol and progesterone. They concluded that the majority of men and all women receiving intrathecal opioids developed hypogonadotrophic hypogonadism and recommended substitutive sex steroids in such patients (61). Currently, there are increasing concerns about intrathecal opioid induced hypogonadism. The mechanism of this action is by alteration of the hypothalamic-pituitary-gonadal axis 
(49). Opioid dosage reduction, opioid rotation, and hormone replacement therapy have all been recommended (62), although to date, there are no established standards for managing this complication.

\section{Respiratory Depression}

Respiratory depression is the most feared complication of intrathecal morphine therapy. Clinically important respiratory depression has been reported following intrathecal morphine $(63,64)$. Respiratory depression due to intraspinal opioids is divided into 2 types; early respiratory depression occurs within 2 hours of drug administration; delayed respiratory depression occurs after 2 hours of drug administration. Early respiratory depression due to intrathecal morphine administration has never been reported. Delayed respiratory depression results from the cephalad migration of the opioid in the CSF and subsequent interaction with the opioid receptors located in the ventral medulla $(65,66)$. There was paucity of reports in the literature on delayed respiratory depression caused by long-term intrathecal morphine therapy. Scherens et al reported one case of respiratory depression while on long-term intrathecal morphine in a 41year-old male with severe neuropathic upper extremity pain due to brachial plexopathy (64). The patient developed progressive deterioration of his pulmonary status, i.e., respiratory acidosis and bradypnea with gradual escalation of his intrathecal morphine dosage over one year period of time. Respiratory compromise improved with dose reduction. Ruan et al encountered a case of respiratory failure following delayed intrathecal morphine pump refill in a 65-year-old lady with intractable chronic low back pain. After being on intrathecal morphine therapy for over 6 months, the patient missed her pump refill appointment due to a family emergency. Following her pump refill 12 days later, she developed respiratory failure, presumably caused by an abolished opioid tolerance due to the empty pump (unpublished data, in preparation). Reversal of respiratory depression can be readily accomplished with the administration of mu antagonist i.e. naloxone or a kappa agonist/mu antagonist i.e. nalbuphine (67-69). Kaiser and Brinton reported an interesting approach of treating intrathecal morphine overdose by aspiration of CSF and replacement with normal saline (70).

\section{Hyperalgesia}

Hyperalgesia induced by intrathecal morphine ad- ministration has been studied in animals (71-75) and humans (76-79). High dose intrathecal morphine administration may produce hyperalgesia and allodynia on rare occasions (80). These are not opioid receptor mediated events (81). Early reports suggested causality by intrathecal high dose morphine to block glycine or gamma-aminobutyric acid (GABA)-mediated inhibition $(82,83)$. Mao et al, and Dunbar and Pulai independently demonstrated that $\mathrm{N}$-methyl-D-aspartate (NMDA) receptor antagonists reduced thermal hyperalgesia caused by intrathecal morphine administration $(84,85)$. Ibuki et al demonstrated the increased content of excitatory amino acid (EAA) neurotransmitter in spinal cord tissue with intrathecal morphine administration (86). Intrathecal morphine induced hyperalgesia has been linked to the increased EAA availability and receptor sensitivity in spinal cord tissue, although other neurotransmitter systems may also play a role (80). Morphine-3-glucuronide, the major metabolite of morphine, has been suggested to induce nociception following intrathecal high dose morphine administration (81). More and more evidence suggests that the development of tolerance and hyperalgesia share common mechanisms (49).

Management approaches include

1. opioid dose reduction

2. opioid rotation to methadone to employ the NMDA antagonist properties of methadone $(87,88)$

3. IV ketamine at subanesthetic doses for NMDA antagonist action $(0.5 \mathrm{mg} / \mathrm{kg}$ bolus and $0.25 \mathrm{mg} / \mathrm{kg} / \mathrm{h})$ $(89,90)$

4. addition of alpha-2-adrenergic agonist, i.e. Clonidine epidurally (4ug/kg in $10 \mathrm{ml}$ NS X 20 minutes followed by $2 \mathrm{ug} / \mathrm{kg} / \mathrm{h}$ for 12 hours) (91)

5. IV lidocaine (1-3mg/kg over 20-30 minutes followed by SC or IV infusion at $0.5-2 \mathrm{mg} / \mathrm{kg} / \mathrm{h})(92)$

6. low dose infusion of naloxone $(0.05 \mathrm{mg} / \mathrm{h})$ to selectively block excitatory activity medicated by $\mathrm{mu}$ receptor (93-95).

\section{Catheter Tip Granuloma}

Inflammatory mass lesions at the tip of intrathecal catheters or catheter tip granulomas have been increasingly recognized over the past 2 decades. Since the first case report by North et al in 1991, on intrathecal catheter tip mass causing spinal cord compression (96), more case studies (97-103) and systemic review (104) have been published. The incidence of intrathecal catheter tip inflammatory mass has been reported to be 0.4 after 2 years of therapy, increasing to $1.16 \%$ 
after 6 years of therapy (105). The incidence of asymptomatic lesions may be much higher (103). It was hypothesized that the high morphine concentration, duration of high concentration infusion, catheter tip location, and poor CSF flow patterns contributed together to the development of catheter tip granulomas (104-106). Allen et al demonstrated that catheter tip granuloma formation depends on the concentration, not the dose of infused morphine (107). The FDA approves preservative free intrathecal morphine in concentrations of $10-25 \mathrm{mg} / \mathrm{ml}$ (108). However, in practice, some clinicians use compounded preservative free morphine at concentrations of $50 \mathrm{mg} / \mathrm{ml}$ so as to prolong the duration for pump refill, which may increase the risk of granuloma formation (108). Nevertheless, Yaksh at al noted $30 \%$ of granulomas developed in patients receiving less than $10 \mathrm{mg} /$ day; $40 \%$ were using morphine concentrations of less than $25 \mathrm{mg} / \mathrm{ml}$ (109). Allen et al also demonstrated that the catheter tip granuloma formation does not depend on opioid receptor activation (110). Yaksh et al found the addition of Clonidine at greater than $250 \mathrm{mcg} /$ day to intrathecal morphine could prevent granuloma development in a canine model (105). Based on this finding, some physicians including author routinely use Clonidine as an adjunct with morphine to inhibit granuloma formation (personal observation, J. Patrick Couch, MD, Physicians' Pain Specialists of Alabama, Mobile, $A L)$. In view of the concentration dependent effect of intrathecal morphine on granuloma formation, Peng and Massucitte recommended that the intrathecal opioid daily dosage and concentrations be kept as low as possible (111). Because catheter-associated masses can cause devastating neurological injury, McMillan suggested initial and periodic radiographic screening such as computed tomography with myelography and high-resolution magnetic resonance scanning (112). In contrast, a consensus panel in 2002 did not believe existing data support routine radiographic surveillance of all patients, instead, the panel emphasized the need for vigilance, regular assessment and a high index of suspicion for granulomas to detect them before the onset of neurological deficit (106). In asymptomatic and minimally symptomatic patients, initiation of saline infusion and/or termination of drug infusion usually result in spontaneous regression of mass lesions (112). In patients with progressive myelopathy or cauda equina syndrome, surgical decompression and removal of the mass lesion are usually required to restore neurological function (113).

\section{SUMMARY}

With the increasing utilization of intrathecal morphine administration for cancer and non-malignant chronic pain, it is important to be aware of the wide variety of non-nociceptive side effects which may also occur in susceptible patients. Physicians utilizing intrathecal morphine therapy should be well aware of the non-nociceptive side effects. It will also be of benefit for eligible spinal pump candidates to be informed and advised about the possible side effects associated with long-term intrathecal morphine administration prior to the placement of permanent morphine infusion pumps.

\section{References}

1. Goldstein A, Lowney, LI, Pal, BK. Stereospecific and nonspecific interactions of the morphine congener levorphanol in the subcelluar fractions of mouse brain. Proc Natl Acad Sci USA 1971;68:1742-1747.

2. Pert CB, Snyder, SH. Opiate receptor: demonstration in nervous tissue. Science 1973;179:1011-1014.

3. Lamotte C, Pert CB, Synder SH. Opiate receptor binding in primate spinal cord: distribution and changes after dorsal root section. Brain Res 1976;112:407412.

4. Yaksh TL, Rudy TA. Analgesia mediated by a direct spinal action of narcotics. Science 1976; 192:1357-1358.
5. Wang JK, Nauss LA, Thomas JE. Pain relief by intrathecally applied morphine in man. Anesthesiology. 1979; 50:149-151.

6. Krames, E. Intraspinal Analgesia for nonmalignant pain, Interventional Pain Management, 2nd Edition, 2001 60; 609-619.

7. Raphael JH, Southall JL, Gnanadurai TV, Treharne GI, Kitas GD; Long-term Experience with implanted intrathecal drug administration systems for failed back syndrome and mechanical low back pain, BMC Musculoskeletal Disord 2002; 3: 17.

8. Deer T, Chapple I, Classen A, Javery D, Stoker, V, Tonder, Burchiel K. Intrathecal drug delivery for treatment of chronic low back pain: Report from the National Outcomes Registry for Low Back Pain. Pain Med 2004; 5:6-13.

9. Kumar K, Kelly M, Pirlot T. Continuous intrathecal morphine treatment for chronic pain of nonmalignant etiology: Long-term benefits and efficacy. Surg Neurol 2001; 55:79-88.

10. Anderson VC, Burchiel KJ. A prospective study of Long-term intrathecal morphine in the management of chronic nonmaligmant pain. Congress of Neurological Surgeons Vol 44(2), Feb. 1999, pp289-300.

11. Holtsman M, Fishman SM. Opioid receptors. In Benton HT, Raja N, Molloy, RE, Liu S, Fishman SM. Essentials of 
Pain Medicine and Regional Anesthesia. 2nd Edition. 2005 Chapter 10:8791.

12. Winkelmuller, $M$, Winkelmuller, W. Long-term effects of continuous intrathecal opioid treatment in chronic pain of non-malignant etiology. J Neurosurg 1996;85:458-467.

13. Chaney, MA. Side effects of intrathecal and epidural opioids. Can J Anaesth 1995; 42:891-903.

14. Chauvin M, Samii K, Schermann JM, Sandour P, Bourdon R, Viars P. Plasma pharmacokinetics of morphine after I.M., extradural and intrathecal administration. Br J Anaesth 1982; 54:843847.

15. Hansdottir V, Hedner T, Woestenborghs R, Nordberg G. The CSF and plasma pharmacokinetics of sufentanil after intrathecal administration. Anesthesiology 1991; 74:264-269.

16. Ionescu, TI, Taverne RH, Houweling PL, Drost RH, Nuijten S, Van Rossum J. Pharmacokinetic study of extradural and intrathecal sufentanil anaesthesia for major surgery. $\mathrm{Br} /$ Anaesth 1991;66:458-464.

17. Di Chiro G. Observations on the circulation of the CSF. Acta Radiol 1996;5:9881002.

18. Johnson A, Bengtsson M, Lofstrom JB, Rane A, Wahlstrom A. Influence of postoperative naloxone infusion on respiration and pain relief after intrathecal morphine. Reg Anesth 1988; 13:146151.

19. Gowan JD. Naloxone infusion after prophylactic epidural morphine: effects on incidence of postoperative side-effects and quality of analgesia. Can J Anaesth 1988;35:143-148.

20. Cousins MJ, Mather, LE. Intrathecal and epidural administration of opioids. Anesthesiology 1984;61:276-310.

21. Morgan M. The rational use of intrathecal and extradural opioids. Br J Anaesthe 1989;63:165-188.

22. Bailey PL, Rhondeau S, Schafer PG, Lu JK, Timmons, BS. Dose-response pharmacology of intrathecal morphine in human volunteers. Anesthesiology 1993;79:49-59.

23. Ballantyne JC, Loach AB, Carr DB. Itching after epidural and spinal opiates. Pain 1988;33:149-160.

24. Hu JW, Dostrovsky JO, Sessle BJ. Functional properties of neurons in cat triageminal subnucleus caudalis (medullary dorsal horn). I. Response to oralfacial noxious and non-noxious stim- uli and projections to thalamus and subnucleus oralis. I Neurophysiol 1981;45:173-192.

25. Scott PV, Fischer HBJ. Intraspinal opiates and itching: a new reflex? $B M$ J 1982; 284:1015-1016.

26. Raj PR. Practical Management of Pain. 3rd Edition. 2000 Common analgesic side effects and treatment. Appendix D. 1025-1026.

27. Yeh HM, Chen LK, Lin CJ, Chan WH, Chen YP, Lin CS. Prophylactic intravenous ondansetron reduces the incidence of intrathecal morphine induced pruritus in patients undergoing cesarean delivery. Anesth Analg 2000.91:172-175.

28. Yazigi A. Prophylactic ondansetron is effective in the treatment of nausea and vomiting but not on pruritus after cesarean delivery with intrathecal sufentanil-morphine. J Clin Anesth 2002. 14:183-186.

29. Charuluxananan S, Kyokong O, Somboonviboon W, Lertmaharit S, Ngampraserwong P, Nimcharoendee K. Nalbuphine versus propofol for treatment of intrathecal morphine-induced pruritus after cesarean delivery. Anesth Analg 2001. 93:162-165.

30. Charuluxananans KO, Somboonviboon W, Narasethakomol A, Promlok P. Nalbuphine versus ondansetron for prevention of intrathecal morphine-induced pruritus after cesarean delivery. Anesth Analg 2003. 96:1789-1793.

31. Raffaeli W, Marconi G, Fanelli G, Taddei S, Borghi GB, Casati A. Opioid-related side-effects after intrathecal morphine: a prospective, randomized, doubleblind dose-response study. Eur I Anaesth 2006; 23:605-610.

32. Synder SH. Opiate receptors in the brain. N Eng J Med 1977;296:266-71.

33. Wang SC, Borison HL. The vomiting center. Archives of neurology and psychiatry 1950;63:928-41.

34. Simoneau II, Hamza MS, Mata HP, Siegel EM, Vanderah TW, Porreca F, Makriyannis A, Malan PT. The cannabinoid agonist WIN55,212-2 suppresses opioid-induced emesis in ferrets. Anesthesiology 2001. 94:882-887.

35. Loper KA, Ready LB, Dorman BH. Prophylactic transdermal scopolamine patches reduce nausea in postoperative patients receiving epidural morphine. Anesth Analg 1989; 68:144-146.

36. Wattwil, M. Postoperative pain relief and gastrointestinal mobility. Acta Chir Scand 1988;550:140-5.

37. Frederich, ME. Nonpain symptom man- agement. Prim Care 2001; 28:299-316.

38. Peterson TK, Husted SE, Rybro L, Schurizek BA, Wernberg, M. Urinary retention during I.M. and extradural morphine analgesia. $\mathrm{Br} /$ Anesth 1982;54:1175-1178.

39. Morgan, $M$. The rational use of intrathecal and extradural opioids. $\mathrm{Br} / \mathrm{An}$ aesth 1989;63:165-188.

40. Rawal N, Mollefors K, Axelsson K, LIngardh G, WIdman B. An experimental study of urodynamic effects of epidural morphine and naloxone reversal. Anesth Analg 1983; 62:641-647.

41. Durant PAC, Yaksh TI. Drug effects on urinary bladder tone during spinal morphine-induced inhibition of the micturition reflex in un-anesthesitized rats. Anesthesiology 1988.68:325.

42. Patt RB, Hassenbusch SJ. Implantable technology for pain control: identification and management of problems and complications. Interventional Pain Management by Steven Waltman 2nd Edition. 2001 Chapter 64:663.

43. Drenger B, Magora F, Evron S, Caine M. The action of intrathecal morphine and methadone on the lower urinary tract in the dog. J Urol 1986; 135:852-855.

44. Wang J, Pennefather S, Russell G. Lowdose naloxone in the treatment of urinary retention during extradural fentanyl causes excessive reversal of analgesia. Br J Anaesth 80:565-566.

45. Practice guidelines for cancer pain management: A report by the American Society Task Force on Pain Management, Cancer Pain Section. Anesthesiology 1996.84:1243-1257.

46. Yaksh TL, Noveihed R. The physiology and pharmacology of spinal opiates. Ann Rev Pharmacol Toxicol 1985;25:433-62.

47. Porreca F, Filla A, Burks TF. Spinal cord mediated opiate effects on gastrointestinal transit in mice. Eur J Pharmacol 1983;86:135-136.

48. Thoren T, Wattwil M. Effects on gastric emptying of thoracic epidural analgesia with morphine or bupivacaine. Anesth Analg 1988;67:687-694.

49. Harris JD, Kotob F. Management of opioid-related side effects. In De LeonCasasola OA, Cancer Pain. Saunders, 2006. Chapter 18:212-230.

50. Mahajan G, Fishman SM. Opioid therapy: adverse effects including addiction. Essentials of Pain Medicine and Regional Anesthesia. 2nd Edition. 2005 Chapter 13:113-123.

51. Liu M, Wittbrodt E. Low-dose oral nal- 
oxone reverses opioid-induced constipation and analgesia. J Pain Symptom Manage 2002; 23:48-53.

52. Anderson VC, Cooke B, Burchiel KJ. Intrathecal hydromorphone for chronic nonmalignant pain: a restrospective study. Pain Medicine Vol 2, No 4, 2001:287-97.

53. Aldrete JA, Couto da Silva JM. Leg edema from intrathecal opiate infusions. Eur J Pain 2000; 4:361-365.

54. Paice JA, Penn R, Shott S. Intraspinal morphine for chronic pain: A retrospective multicenter study. J Pain Symptom Manage 1996; 11:71-80.

55. Sidi A, Davidson JT, Behar M, Olshwang D. Spinal narcotics and central nervous system depression. Anaesthesia 1981;36:1044-1047.

56. Paulus DA, Paul W, Munson ES. Neurological depression after intrathecal morphine. Anesthesiology 1981;54:517518.

57. Christie JM, Meade WR, Markowsky S. Paranoid psychosis after intrathecal morphine. Anesth Analg 1993;77:1298 1299.

58. Rawal N, Arnér, S, Gustafsson LL, Allvin, $R$. Present state of extradural and intrathecal opioid analgesia in Sweden. Br. J Anaesth 1987;59:791-799.

59. Bruera E, Miller MJ, Macmillan K, Kuehn N. Neuropsychological effects of methylphenidate in patients receiving a continuous infusion of narcotics for cancer pain. Pain 1992.48:163-66.

6o. Webster L, Andrews M, Stoddard G. Modafinil treatment of opioid-induced sedation. Pain Medicine 2003; 4:135140.

61. Abs R, Verhelst J, Maeyaert J, Van Buyten JP, Opsomer F, Adriaensen H, Verlooy J, Van Havenbergh T, Smet M, Van Acker K. Endocrine Consequences of long-term intrathecal administration of opioids. I of Clinic Endocrininology \& Metablism 2000 Vol. 85, No. 6:22152222.

62. Katz N. The impact of opioids on the endocrine system. 2005. Pain Management Rounds 1.

63. Gustafsson LL, Schildet B, Jacobsen K. Adverse effects of extradural and intrathecal opiates: report of a nationwide survey in Sweden. Br. J. Anaesth 1982;54:479-486.

64. Scherens A, Kagel T, Zenz M, Maier C. Long-term respiratory depression induced by intrathecal morphine treatment for chronic neuropathic pain. Anesthediology 2006;105:431-433.
65. Holtsman M, Fishman SM. Opioid Receptors. Chapter 10. Essentials of Pain Medicine and Regional Anesthesia. 2005 2nd Edition.

66. Shook JE, Watkins WD, Camporesi EM. Differential roles of opioid receptors in respiration, respiratory disease, and opioid-induced respiratory depression. Am Rev Respir Dis 1990; 142:895-909.

67. Baise GA, McMichan JC, Nugent M, Hollier LH. Nalbuphine produces side effects while reversing narcotic induced respiratory depression. Anesth Analg 1986; 65(Suppl):S19.

68. Hammond JE. Reversal of opioid associated late onset respiratory depres. sion by nalbuphine hydrochrloride. Lancet. 1984; 2:1208.

69. Schmauss C, Doherty C, Yaksh TL. The analgesic effects of an intrathecally administered partial opiate agonist, nalbuphine hydrochloride. Eur J Pharmacol 1983; 86:1.

70. Kaiser KG, Bainton CR. Treatment of intrathecal morphine overdose by aspiration of cerebrospinal fluid. Anesth Analg 1987; 66:475.

71. Yaksh TL, Harty GJ, Onofrio BM. High doses of spinal morphine produces a nonopiate receptor-mediated hyperesthesia: clinical and theoretic implication. Anesthesiology 1986; 64:590597.

72. Dunbar SA, Karamian IG. Periodic abstinence enhances nociception without significantly altering the antinociceptive efficacy of spinal morphine in the rat. Neurosci Lett 2003; 344:145-148.

73. Johnston IN. A role for proinflammatory cytokines and fractalkine in analgesia, tolerance, and subsequent pain facilitation induced by chronic intrathecal morphine. J Neurosci 2004; 24:73537365.

74. Mao J. Chronic morphine induces downregulation of spinal glutamate transporters: Implications in morphine tolerance and abnormal pain sensitivity. $J$ Neurosci 2002; 22:8312-8323.

75. Vanderah TW. Dynorphin promotes abnormal pain and spinal opioid antinociceptive tolerance. I Neurosci 2000; 20:7074-7079.

76. Ali NMK. Hyperalgesic response in a patient receiving high concentration of spinal morphine(Letter). Anesthesiology 1986; 65:449.

77. Wilson GR, Reisfield, GM. Morphine hyperalgesia: A case report. Am J Hosp Palliat Care 2003; 20:459-461.

78. De Conno F, Caraceni A, Martini C, Spol- di E, Salvetti M, Ventafridda V. Hyperalgesia and myoclonus with intrathecal infusion of high-dose morphine. Pain 1991; 47:337-339.

79. Parisod E. Allodynia after acute intrathecal morphine administration in a patient with neuropathic pain after spinal cord injury. Anesth Analg 2003; 97:183186.

80. Angst MS, Clark JD. Opioid induced hyperalgesia: A Qualitative systematic review. Anesthesiology 2006; 104:570587.

81. Sakurada T, Komatsu T, Sakurada S. Mechanisms of nociception evoked by intrathecal high-dose morphine. NeuroToxicology 2005; 26: 801-809.

82. Woolf CJ. Intrathecal high hose morphine produces hyperalgesia in the rat. Brain Res 1981; 209:491-495.

83. Yaksh TL, Harty GL. Pharmacology of the allodynia in rats evoked by high dose intrathecal morphine. I Pharmcol Exp Ther 1988; 244:501-507.

84. Mao J, Price DD, Mayer DJ. Thermal hyperalgesia in association with the development of morphine tolerance in rats: roles of excitatory amino acid receptors and protein kinase C. J Neurosci 1994; 14:2301-2312.

85. Dunbar SA, Pulai IJ. Repetitive opioid abstinence causes progressive hyperalgesia sensitive to $\mathrm{N}$-methyl-D-aspartate receptor blockade in the rat. J Pharmacol Exp Ther 1998; 284:678-686.

86. Ibuki T, Marsala M, Masuyama T, Yaksh TL. Spinal amino acid release and repeated withdrawal in spinal morphine tolerant rats. $\mathrm{Br} /$ Pharmacol 2003; 138:689-697.

87. Davis AM, Inturrisi CE. d-Methadone blocks morphine tolerance and N-methyl-aspartate-induced hyperalgesia. J Pharmacol Exp Ther 1999; 289:10481053.

88. Inturrisi CE. Pharmacology of methadone and its isomers. Minerva Anestesiol 2005; 71:435-437.

89. Bell RF, Eccleston C, Kalso E. Ketamine as adjuvant to opioid for cancer pain: A qualitative systematic review. I Pain Symptom Manage 2003; 26:867-875.

90. De Kock M, Lavand'homme P, Waterloos H. "Balanced analgesia": in the perioperative period: is there a place for Ketamine? Pain 2001; 92:373-380.

91. Quan DB, Wandres DL, Schroeder DJ. Clonidine in pain management. Ann Pharmacother 1993; 27:313-315.

92. Ferrini R, Paice JA. How to initiate and monitor infusional lidocaine for severe 
and/or neuropathic pain. J Support Oncol 2004; 2:90-94.

93. Crain SM, Shen KF. Ultra-low concentrations of naloxone selectively antagonize excitatory effects of morphine on sensory neurons, thereby increasing its antinociceptive potency and attenuating tolerance/dependence during chronic cotreatment. Proc Natl Acad Sci USA 1995; 92:1540-1544.

94. Crain SM, Shen KF. Acute thermal hyperalgesia elicited by low-dose morphine in normal mice is blocked by ultra-low-dose naltrexone, unmasking potent analgesia. Brain Res 2001; 888:75-82.

95. Mercadante S, Villari P, Ferrera P. Naloxone in treating central adverse effects during opioid titration for cancer pain. $J$ Pain Symptom Manage. 2003; 26:691693.

96. North RB, Cutchis RN, Epstein JA, Mong DM. Spinal cord compression complicating subarachnoid infusion of morphine: case report and laboratory experience. Neurosurgery 1991; 29:778784 .

97. Schuchard M, Lanning R, North R, Reig $R$, Krames E. Neurological sequelae of intraspinal drug delivery systems. Neuromodulation 1998; 1:137-148.

98. Langsam, A. Spinal cord compression by catheter granulomas in high-dose intrathecal morphine therapy: Case report. Neurosurgery 1999; 44:689-691.

99. Cabbell KL, Taren JA, Sagher O. Spinal cord compression by catheter granulo- mas in high-dose intrathecal morphine therapy: case report. Neurosurgery 1998; 42:1176-1180.

100. Blount JP, Remley KB, Yue SK, Erickson DL. Intrathecal granuloma complicating chronic spinal infusion of morphine: report of three cases. I Neurosurg 1996; 84:272-276.

101. Bejjani GK, Karim NO, Tzortzidis F. Intrathecal granuloma after implantation of a morphine pump: case report and review of the literatures. Surg Neurol 1997; 48:288-291.

102. Aldrete JA, Vascello LA, Ghaly R, Tomlin $D$. Paraplegia in a patient with an intrathecal catheter and a spinal cord stimulator. Anesthesiology 1994; 81:15421545

103. Toombs JD, Follett KA, Rosenquist RW, Benton LM. Intrathecal catheter tip inflammatory mass: a failure of Clonidine to protect. Anesthesiology 2005; 102:687-690.

104. Coffey, RJ, Burchiel, K. Inflammatory mass lesions associated with intrathecal drug infusion catheters: report and observations on 41 patients. Neurosurgery 2002; 50:78-87.

105. Yaksh T, Hassenbusch S, Burchiel K, Hildebrand KR, Page LM, Coffey RJ. Inflammatory masses associated with in trathecal drug infusion: a review of preclinical evidence and human data. Pain Med 2002; 3: 300-312.

106. Hassenbusch S, Burchiel K, Coffey RJ, Cousins MJ, Deer T, Hahn MB, Du Pen $\mathrm{S}$, Follett KA, Krames E, Rogers JN, Sa- gher O, Staats PA, Wallace M, Willis $K D$ (2002). Management of intrathecal catheter-tip inflammatory masses: A consensus statement. Pain Med 2002;3:313-323.

107. Allen JW, Horais KA, Tozier NA, Wegner K, Corbeil JA, Mattrey RF, Rossi SS, Yaksh TL. Time course and role of morphine dose and concentration in intrathecal granuloma formation in dogs. Anesthesiology 2006; 105:508-509.

108. Follett, KA. Intrathecal opioid infusion. Anesthesiology 2004; 101:256.

109. Yaksh, TL, Horais KA, Tozier NA, Allen JW, Rathbun M, Rossi SS, Sommer C, Meschter C, Richter PJ, Hildebrand KR. Chronically infused intrathecal morphine in dogs. Anesthesiology 2003; 99:174-197.

110. Allen, JW, Horais KA, Tozier NA, Yaksh TL. Opiate pharmacology of intrathecal granulomas. Anesthesiology 2006; 105:590-598.

111. Peng P, Massucitte EM. Spinal cord compression from intrathecal catheter-tip inflammatory mass: Case report and a review of etiology. Reg Anesth Pain Med 2004: 29:237-242.

112. McMillan, MR. Intrathecal morphine and inflammatory masses. Anesthesiology 2004; 101:255.

113. Coffey, RJ, Burchiel, K. Inflammatory mass lesions associated with intrathecal drug infusion catheters: Report and observations on 41 patients. Neurosurgery 2002; 50: 78-87. 
